\title{
O direito humano à educação e as migrações internacionais contemporâneas: notas para uma agenda de pesquisa
}

Giovanna Modé Magalhães

Mestra em Sociologia

da Educação pela

Faculdade de Educação

da Universidade de São

Paulo.
Resumo: 0 objetivo do presente artigo é discutir o lugar das populações migrantes nos debates sobre o direito humano à educação. Consideraremos em nossa análise os novos contornos das migrações internacionais contemporâneas, realidade cada vez mais notável nas grandes cidades, inclusive nas brasileiras. Faremos uma breve reflexão sobre a noção contemporânea de direito humano à educação para centrar-nos na seguinte indagação: o que seria garantir para os e as imigrantes - estejam eles regularizados ou não - a realização de seus direitos educativos? Destacaremos ainda algumas especificidades do caso particular dos migrantes bolivianos nas escolas públicas de São Paulo, a luta por seus direitos educativos e alguns desafios para uma agenda de pesquisa sobre o tema.

Palavras-chave: Direito Humano à Educação. Legislação Educacional. Imigrantes. Migrações Internacionais. 
A educação terá por objetivo o pleno desenvolvimento da personalidade humana e fortalecimento do respeito aos direitos humanos e às liberdades fundamentais; favorecerá a compreensão, a tolerância e a amizade entre todas as nações e todos os grupos étnicos ou religiosos. (Declaração Universal dos Direitos Humanos, 1948)

A escola faz parte das instituições modernas que pressupõem um enraizamento, para as quais, no limite, todo ser humano que se move parece uma anomalia. (MARTINS, 2001, p. 24)

\section{INTRODUÇÃO}

O propósito deste texto é discutir o lugar das populações migrantes nos debates sobre o direito humano à educação. Ainda que direitos humanos seja tema presente nas pesquisas recentes sobre fenômenos migratórios, no Brasil ainda são escassos os estudos que relacionam o direito à educação e a população imigrante, considerando os novos contornos das migrações internacionais contemporâneas. Por outro lado, trata-se de uma realidade cada vez mais notável nas grandes cidades, inclusive nas brasileiras. Trataremos de realizar uma breve reflexão sobre a noção contemporânea ${ }^{1}$ de direito humano à educação para, em seguida, centrar-nos na seguinte indagação: o que seria garantir para os e as imigrantes - estejam eles regularizados ou não - a realização dos direitos educativos? 0 que seria pensar a educação de pessoas desenraizadas, como lembra Martins (2001), numa das instituições mais territorializadas da modernidade?

Destacaremos, a título de exemplo, o caso particular dos migrantes bolivianos nas escolas públicas de São Paulo, a luta por seus direitos educativos e alguns desafios para uma agenda de pesquisa sobre o tema. A capital paulista está entre as metrópoles caracterizadas historicamente pelo recebimento de imigrantes. Sua dinâmica atual continua atraindo não só brasileiros/as de diversos outros estados, mas também estrangeiros, de uma maneira distinta das grandes migrações que caracterizaram o século 19 e a primeira metade do século 20. Com novos contornos e inserida em um contexto bastante diferente, a metrópole tem como um dos notáveis fluxos de pessoas aquele

1 A escolarização das correntes migratórias predominantes no final do século 19 e até meados do século 20 foi objeto de pesquisas, como a de DEMARTINI (2005), que trata dos grupos de alemães, japoneses e portugueses nas escolas de São Paulo neste período, considerando as relações de suas famílias com o projeto educativo. A década de 30, quando durante o governo de Getúlio Vargas as escolas de grupos estrangeiros são obrigadas a nacionalizarem-se, é também bastante mencionada em estudos. As análises sobre o que se sucedeu posteriormente nos pareceram mais escassas. 
originado nos países vizinhos latino-americanos². Dentre esses, o maior, segundo a nacionalidade, é o de bolivianos/as, que se sobressai tanto nas estatísticas oficiais como nas estimativas de pessoas em situação irregular, ou seja, sem a documentação necessária para viver e trabalhar em território brasileiro (MAGALHAES, 2010). Em seguida, destacam-se as populações peruanas e paraguaias com forte presença no território paulistano. Na rede municipal de ensino, bem como na rede estadual, são centenas de estudantes matriculados oriundos desses países, além daqueles que estão em idade escolar e fora de qualquer escola. O que seria garantir a essas populações seu direito humano à educação?

Frente a esta pergunta, faz-se necessário considerar como uma constante desse exercício de análise, as disputas e tensões em torno do campo dos Direitos Humanos, hoje afirmado globalmente. Um primeiro aspecto, nesse sentido, são os diversos debates entre cidadania, direitos humanos e imigração, com especial ênfase nas contradições entre os direitos de todos e os direitos dos cidadãos. Estar em condição irregular num determinado país significa viver na ilegalidade sob o constante risco de deportação, já que o direito de emigrar não assegura o direito de entrar em outro país - processo esse que deve ser autorizado pelos Estados nacionais. Porém, o fato de lá estar não tira, do indivíduo ou do grupo, direitos fundamentais inerentes à condição humana, e entre eles os direitos educativos.

Pode-se afirmar que existe, no escopo desse debate, um consenso sobre a necessidade de se garantir a esses não-cidadãos a tutela necessária até que sua situação seja regularizada (LAFER, 1988). No entanto, esse tem sido um ponto clássico de tensão não somente na análise, mas nas políticas e práticas contemporâneas. Como lidar com uma população que um determinado Estado não quer receber - e que no limite já está em seu território? Pessoas que naquele momento não são “necessárias”, caso contrário, como ressaltou Sayad (1998), seriam facilmente regularizáveis. De certa maneira, impera uma lógica de que garantir direitos aos migrantes indocumentados incentivaria a chegada de outros iguais a eles (REIS, 2007). Como lembra Hannah Arendt (1989), são populações como os deslocados de guerra, refugiados e os apátridas que lembram aos Estados e à comunidade internacional o desafio de se garantir direitos a pessoas que não pertencem a comunidade nacional alguma.

Ainda que dentre os bolivianos/as que vivem no Brasil haja diversidade sobre situação migratória, trabalhista e de condições de vida - há, por exemplo, uma minoria que migra para estudar em universidades, pós-graduação ou em programas de intercâmbio - nosso texto refere-se à população que se encontra direta ou indiretamente vinculada de forma precária às oficinas têxteis, concentradas majoritariamente na região central da cidade. 


\section{A EDUCAÇÃO E OS DIREITOS HUMANOS}

A construção de normativas internacionais inscritas no campo do Direito Internacional dos Direitos Humanos consolidou na legislação internacional o direito à educação para todas as pessoas. Segundo Bobbio (1992, p. 75), “não existe atualmente nenhuma carta de direitos que não reconheça o direito à instrução". 0 direito à educação não deixa de ser um campo de disputas, em que se cruzam diversos entendimentos sobre o que seria a realização desse direito. Como se educa, quem se educa e para que se educa? Qual o sentido dessa educação para todos?

A Declaração Universal dos Direitos Humanos, de 1948, afirma o direito à educação com base em três princípios: universalidade; gratuidade e obrigatoriedade. Seu art. 26 diz que o ensino será gratuito ao menos nos graus "elementares e fundamentais" e obrigatória em seu nível primário. Diz ainda que a instrução técnica e profissional deverá ser generalizada e o acesso aos estudos superiores “em função de seus respectivos méritos”. Com relação aos propósitos da educação, o texto resolve da seguinte maneira:

A educação terá por objetivo o pleno desenvolvimento da personalidade humana e fortalecimento do respeito aos direitos humanos e às liberdades fundamentais; favorecerá a compreensão, a tolerância e a amizade entre todas as nações e todos os grupos étnicos ou religiosos, e promoverá o desenvolvimento das atividades das Nações Unidas para a manutenção da paz (ORGANIZAÇÃO DAS NAÇÕES UNIDAS, 1948).

Os preceitos foram mais tarde reafirmados no Pacto Internacional de Direitos Econômicos, Sociais e Culturais, de 1966, e numa lista de outros instrumentos, todos eles ratificados pelo Brasil. No caso do continente americano, aplica-se ainda a legislação regional acordada no âmbito do Sistema Interamericano de Direitos Humanos, nesse caso especificamente o Protocolo Adicional à Convenção Americana sobre Direitos Humanos em matéria de Direitos Econômicos, Sociais e Culturais - Protocolo de San Salvador, de 1988 (art. 13). Essa normativa afirma que toda pessoa tem direito à educação, e que esta deverá orientar-se para o pleno desenvolvimento da personalidade humana e no sentido de sua dignidade, e deverá fortalecer o respeito pelos direitos humanos, pelo pluralismo ideológico, pelas liberdades fundamentais, pela justiça e pela paz.

Um desafio contemporâneo latente nesta seara é o aprofundamento do texto mínimo acordado na Declaração de 1948 e nos pactos posteriores, mantendo os princípios lá afirmados, mas traduzindo-os para a aplicação em legislações, planos e práticas. Algumas instâncias intergovernamentais, 
como os comitês de seguimento de cada uma das convenções mencionadas, tiveram papel relevante nesse sentido, em especial o Comitê de Direitos Econômicos, Sociais e Culturais (DESC), constituído em 1985 no âmbito da Organização das Nações Unidas (ONU) para monitorar o cumprimento do já mencionado Pacto de Direitos Econômicos, Culturais e Sociais de 1966.

Em sua Observação Geral n¹1, esse Comitê explicita a importância vital do direito à educação, também para a realização dos demais direitos. E reforça que, além de um direito classificado entre os econômicos, sociais e culturais, a educação compreende todos esses direitos ao mesmo tempo.

também, de muitas formas, é um direito civil e um direito político situado no centro da realização plena e eficaz desses direitos. De tal maneira, o direito à educação é a epítome da indivisibilidade e da interdependência de todos os direitos humanos (COMITÊ DE DIREITOS ECONÔMICOS, SOCIAIS e CULTURAIS, 1999).

Nos debates sobre quais as implicações de uma educação universal, gratuita e obrigatória, destacou-se, entre outras, a contribuição de Katarina Tomasevski, relatora especial das Nações Unidas sobre o Direito à Educação, entre 1998 e 2004. Tanto em seus relatórios enviados aos países e entregues oficialmente à então Comissão de Direitos Humanos da ONU, como na literatura que deixou disponível, Tomasevski se notabilizou pela insistência na aproximação da educação com o campo dos direitos humanos, problematizando especialmente o papel do Estado. Comenta a autora sobre o notável paradoxo nesse sentido: o principal protetor desses direitos - a autoridade em que se deve apoiar para que sejam cumpridos - é também o principal violador.

Uma das implicações de se perceber a educação como um direito humano, diz a autora, é entender que um compromisso não cumprido em relação à realização desse direito deve ser visto como uma violação. Sob esta ótica, os compromissos assumidos pelos Estados de universalizar a educação passam a ser vistos como uma obrigação legal e os mesmos devem estar sujeitos a sanções legais, além de terem a obrigação de providenciar a reparação, compensar as vítimas e assegurar que violações semelhantes não voltem a ocorrer.

Para a autora, a busca pela realização plena do direito humano à educação deve incluir, simultaneamente, três dimensões: o direito humano à educação; os direitos humanos na educação; e os direitos humanos através da educação (TOMASEVSKI, 2004).

Na dimensão do acesso, pilares centrais do direito humano à educação, são consideradas as condições proporcionadas pelo Estado para que esse 
direito seja efetivado, tais como o financiamento adequado, condições de trabalho para os docentes, bem como uma legislação local que assegure o acesso gratuito e a permanência de todos, sem discriminações, nos sistemas escolares.

Com relação aos direitos humanos na educação, a autora destaca, por exemplo, a oferta de um ambiente saudável e seguro para a aprendizagem; bem como a instrução na língua própria dos alunos; a liberdade em relação a censuras e o reconhecimento das crianças como sujeitos. Ainda como fatores fundamentais nesse sentido, ela propõe o desenvolvimento de políticas específicas adaptadas para a aprendizagem de minorias que não têm suas especificidades contempladas no ensino tradicional, tais como estudantes indígenas, migrantes, pessoas com deficiência etc. Esse reconhecimento implica inclusive em mais gastos por parte do poder público - formação de professores e a produção de livros didáticos, por exemplo, considerando-se que a diversidade lingüística e cultural requer mais investimentos.

Por fim, os direitos humanos através da educação estariam intrinsecamente ligados à finalidade da relação educativa. Essa dimensão demonstra a preocupação com a formação de sujeitos capazes de agirem no sentido de proteger e promover esses direitos (TOMASEVSKI, 2004). É inaceitável, ressalta a autora, a realidade de uma educação "anti” direitos humanos, e cita diversos exemplos paradigmáticos com conteúdos discriminatórios nos livros didáticos, práticas autoritárias e preconceituosas, entre outros. O desafio seria, portanto, eliminar por completo esse tipo de conduta na educação para que haja espaço para a promoção dos direitos humanos, bem como promover a formação para o combate aos abusos de poder na própria educação, estimulando para isso a autonomia e o senso crítico.

Essa construção foi traduzida de outra maneira por Tomasevski(2006) no arcabouço que ficou conhecido como "Esquema dos 4As", um conjunto de critérios capaz de unir dimensões necessárias à realização plena do direito humano à educação. Seriam critérios para uma educação disponível, acessível, aceitável e adaptável (os “4As" seriam devido à sigla em inglês: available; accessible; acceptable; adaptable) - sem qualquer um deles, o direito à educação estaria sendo violado. Disponível no sentido de que haja instituições e programas de ensino em quantidade suficiente; acessível, sem obstáculos econômicos, legais ou discriminatórios; aceitável, contando com padrões mínimos de qualidade; e adaptável em relação à flexibilidade capaz de responder às necessidades dos estudantes, nos mais diferentes contextos 
sociais e culturais. Essa estrutura foi adotada pelo Comitê DESC (1999), e documentada em suas Observações Gerais $n^{\circ} 13$ sobre o direito à educação, durante o 21 ํㅜㅇo pero de sessões nos seguintes termos:

Si bien la aplicación precisa y pertinente de los requisitos dependerá de las condiciones que imperen en un determinado Estado Parte, la educación en todas sus formas y en todos los niveles debe tener las siguientes cuatro características interrelacionadas:

a) Disponibilidad. Debe haber instituciones y programas de enseñanza en cantidad suficiente en el ámbito del Estado Parte. Las condiciones para que funcionen dependen de numerosos factores, entre otros, el contexto de desarrollo en el que actúan; por ejemplo, las instituciones y los programas probablemente necesiten edificios u otra protección contra los elementos, instalaciones sanitarias para ambossexos, agua potable, docentes calificados con salarios competitivos, materiales deenseñanza, etc; algunos necesitarán además bibliotecas, servicios de informática, tecnología de la información, etc.;

b) Accesibilidad. Las instituciones y los programas de enseñanza han de ser accesibles a todos, sin discriminación, en el ámbito del Estado Parte. La accesibilidad consta detres dimensiones que coinciden parcialmente:

i) No discriminación. La educación debe ser accesible a todos, especialmente a los grupos no vulnerables de hecho y de derecho, sin discriminación por ninguno de los motivos prohibidos (véanse los párrafos 31 a 37 sobre la no discriminación).

ii) Accesibilidad material. La educación ha de ser asequible materialmente, yasea por su localización geográfica de acceso razonable (por ejemplo, una escuela vecinal) o por medio de la tecnología moderna (mediante el acceso a programas de educación a distancia).

iii) Accesibilidad económica. La educación ha de estar al alcance de todos. Estadimensión de la accesibilidad está condicionada por las diferencias de redacción del párrafo 2 del artículo 13 respecto de la enseñanza primaria, secundaria y superior: mientras que la enseñanza primaria ha de ser gratuita para todos, se pide a los Estados Partes que implanten gradualmente la enseñanza secundaria y superior gratuita.

c-) Aceptabilidad. La forma y el fondo de la educación, comprendidos los programas de estudio y los métodos pedagógicos, han de ser aceptables (por ejemplo, pertinentes, adecuados culturalmente y de buena calidad) para los estudiantes y, cuando proceda, los padres; este punto está supeditado a los objetivos de la educación mencionados enel párrafo 1 del artículo 13 y a las normas mínimas que el Estado apruebe en materiade enseñanza (véanse los párrafos 3 y 4 del artículo 13);

d) Adaptabilidad. La educación ha de tener la flexibilidad necesaria para adaptarse a las necesidades de sociedades y comunidades en transformación y responder a las necesidades de los alumnos en contextos culturales y sociales variados.

O arcabouço acima continua sendo um referencial essencial na perspectiva da afirmação da educação como direito humano. Muitos pesquisadores ou organizações continuam modificando e aprofundando o entendimento do que seria a realização plena do direito à educação. Pesquisadores da 
Universidade de Princeton acrescentaram um outro "A", de Accountability como um novo critério - que seria a dimensão relacionada à participação, controle social, transparência nos gastos públicos para fins educativos.

OS IMIGRANTES E O DIREITO HUMANO À EDUCAÇÃO

Ainda que esse amplo arcabouço garanta a todas as pessoas os direitos mencionados, ou seja, tais garantias legais são de todos e todas e não somente dos nacionais de um determinado país, os direitos educativos voltaram a ser reafirmados nas normativas internacionais que tratam especificamente das populações migrantes e dos refugiados. A Convenção Internacional sobre a Proteção de Todos os Trabalhadores Migrantes e Seus Familiares registra em seu art. 30 que o filho de um trabalhador migrante tem o direito fundamental de acesso à educação em condições de igualdade de tratamento com os nacionais do Estado interessado (ORGANIZAÇÃO DAS NAÇÕES UNIDAS, 1990).

O texto reforça, ainda, a proibição de que seja negado ou limitado o acesso a estabelecimentos públicos de ensino por motivo de situação irregular dos pais ou da própria criança. A Convenção ressalta, finalmente, que os Estados onde trabalham migrantes, em colaboração com os Estados de origem, deverão, quando procedente, aplicar uma política encaminhada a facilitar a integração dos filhos de trabalhadores migrantes no sistema escolar local, particularmente em relação ao ensino do idioma local.

Interessante notar que essa Convenção - a que mais aborda o tema em maneira explícita - não se refere a todas as pessoas migrantes, mas sim aos filhos dos trabalhadores/as migrantes. Basta atentar para seu nome: Convenção Internacional sobre a Proteção de Todos os Trabalhadores Migrantes e Seus Familiares. Questão presente nos estudos sobre os novos fluxos migratórios, as pessoas que migram para ocupar um determinado ramo da produção nacional, em geral aqueles que seus nacionais não desejam, parecem representar um fluxo migratório mais natural ou esperado do que os demais.

A literatura mostra que os fluxos contemporâneos são bastante mais complexos e já não respondem à lógica binária de atração/repulsão econômica, como se acreditava anteriormente. Já no final dos anos 70, Sayad (1998, p. 55) levantava um tema que viria a ser amplamente debatido nos anos seguintes, que era a tensão entre o trabalhador e o cidadão na sociedade receptora: deseja-se a força de trabalho, pois muitas vezes sabe-se que sua mão de obra é imprescindível, mas não a presença daquele ser humano em sua plenitude. "Ser imigrante e desempregado é um paradoxo", dizia o autor. 
Para os fins de nosso estudo, especificamente com relação aos direitos educativos, os e as imigrantes têm esbarrado em violações ligadas à acessibilidade (toda a questão de documentação exigida como uma primeira barreira notável), bem como de aceitabilidade (não é aceitável uma educação que discrimina) e adaptabilidade (diferenças que estão sendo ignoradas, a começar pela linguística). Interessante perceber que, em países da Europa, Estados Unidos e outros receptores de imigrantes, a presença de estrangeiros nos centros educativos é um dos fatores centrais que têm motivado os debates sobre diferença na escola, enquanto aqui o grupo que faz parte das novas migrações internacionais é ainda cercado de invisibilidade, configurando-se dessa forma um campo novo para estudos.

Longe de afirmar que naqueles países a questão encontra-se equacionada, ao contrário, é evidentemente mais tensa. Na Itália, por exemplo, foi anunciada a intenção do governo de limitar o número de estudantes imigrantes por escola a 30\%, caso contrário "não seria uma migração apropriada, não se integrariam aos colegas italianos” (REUTERS BRASIL, 2009), disse a ministra de educação, que depois anunciou a separação de alunos imigrantes dos italianos. Na Alemanha, o sistema dividido por mérito dos alunos tem sido alvo de críticas diversas, por concentrar nas piores escolas os alunos imigrantes, em sua maioria, turcos. E finalmente 0 alarmante e recente caso grego, em que o primeiro ministro afirmou que não havia vagas para estrangeiros nas escolas do país e, em seguida, um partido conhecido por ser a favor da expulsão de imigrantes solicitou a lista de crianças matriculadas para confirmar que "de fato só havia gregos estudando em seu país” (OPERA MUNDI , 2012).

Se, por um lado, as tensões são mais evidentes, por outro, esses grupos são mais visíveis e, aos poucos, observam-se alguns indícios, ainda que pontuais, de políticas que consideram suas especificidades. Em Portugal, por exemplo, os imigrantes recebem folheto explicativo que ressalta o direito à educação independentemente da situação no país, bem como a oferta extra do idioma aos que não falam português; na Dinamarca, crianças monolíngues e bilíngues aprendem juntas na mesma escola - as crianças migrantes recebem até dois anos de instrução básica em dinamarquês como um segundo idioma em classes separadas até que estejam prontas para as aulas regulares. A aprendizagem inclui materiais gratuitos em ambos idiomas. 
OS IMIGRANTES NA LEGISLAÇÃO NACIONAL SOBRE A EDUCAÇÃO: SÃO PARTE DO 'TODOS'?

O Brasil assinou todos os instrumentos internacionais citados anteriormente - exceto a Convenção Internacional sobre a Proteção dos Direitos de Todos os Trabalhadores Migrantes e seus Familiares (ONU, 1990). No plano interno, o país afirma o ensino fundamental como um direito de todos desde a Constituição de 1934 , que, inspirada nas constituições alemãs e espanholas, dedicou um capítulo todo à educação inaugurando o chamado Direito Educacional Constitucional (HADDAD, 2007).

AConstituição Federal de 1988 é certamente um marco para a educação escolar, ao declarar toda a educação básica como direito público subjetivo, exigível por qualquer pessoa nos sistemas de justiça. Diz o art. 205 que "a educação, direito de todos e dever do Estado e da família, será promovida e incentivada com a colaboração da sociedade, visando ao pleno desenvolvimento da pessoa, seu preparo para o exercício da cidadaniae sua qualificação para o trabalho" (BRASIL, 1988). Dois anos mais tarde, em 1990, é aprovado o Estatuto da Criança e do Adolescente (ECA), regulamentando algumas das premissas educacionais que estavam na Constituição para a faixa etária até 18 anos. Em seu art. 53 garante "igualdade de condições para o acesso e permanência na escola”, bem como o direito de acesso à escola pública e gratuita próxima à sua residência (BRASIL, 1990). O ECA reafirma o dever do Estado de assegurar à criança e ao adolescente o ensino fundamental, obrigatório e gratuito, inclusive para os que não tiveram acesso na idade própria, bem como a progressiva extensão da gratuidade e obrigatoriedade do Ensino Médio e o atendimento em Educação Infantil. Nota-se que, em todo o texto, que o Estatuto fala nos direitos de todas as crianças e adolescentes sem discriminação se nascidas ou não no Brasil.

Em que pese o valor da Constituição Nacional e do Estatuto da Criança e do Adolescente, que afirmam a educação como um direito de todas as pessoas e não apenas dos cidadãos e cidadãs brasileiros -, o anacronismo do Estatuto do Estrangeiro (Lei 6815/80) já causou (e ainda causa em alguns casos) entraves de diversas ordens para a realização dos direitos das populações imigrantes, em particular daqueles em situação irregular. Esse instrumento legal, cujo teor é completamente dissociado das normativas de Direitos Humanos e da Constituição de 1988 que viria alguns anos depois, traz a visão do estrangeiro como uma ameaça à segurança nacional, alguém contra quem o país deve defender-se. Com relação ao acesso à escola, diz que apenas 
estrangeiros “devidamente registrados" poderiam efetivar matrícula (art. 48) em qualquer grau de ensino (BRASIL, 1980).

Com base nessa lei, em janeiro do ano de 1990, foi aprovada a Resolução n. 9 pela Secretaria de Educação do Estado de São Paulo, que proibia crianças sem documentos de frequentarem a escola, particular ou pública. 0 documento deliberava que os estabelecimentos de ensino deveriam exigir o Registro Nacional de Estrangeiro - RNE, fornecido pela Polícia Federal, e encaminhar a documentação às Coordenadorias de Ensino, que tinham a obrigação de entregar a relação dos estudantes à Secretaria de Educação, órgão que, por sua vez, deveria enviar ofício com a informação ao Ministério da Justiça.

Antes de tal Resolução, os alunos estrangeiros, inclusive aqueles em situação irregular, vinham normalmente frequentando a escola (BONASSI, 2000, p. 173). Esta resolução cancelava as matrículas das crianças e adolescentes sem documentação. Os relatos incluíam não só o impedimento a novos estudantes nestas condições, como também a expulsão de crianças e jovens no meio do ano letivo. Diante da insistência dos pais, houve casos de aceitação como "ouvintes" até o final do ano. Estima-se que cerca de 400 crianças e adolescentes tenham deixado a escola naquelas circunstâncias no Estado de São Paulo.

Diante daquele cenário, incoerente com as normas internacionais, a Constituição Federal ou o recém-aprovado Estatuto da Criança e do Adolescente, algumas organizações da sociedade civil, entre elas a Comissão de Justiça e Paz e o Centro Pastoral dos Migrantes, pediram formalmente a revogação da Resolução n. 9. Elaboraram conjuntamente um dossiê relatando o problema, com documentação sobre as dificuldades, uma lista de crianças e jovens que estavam fora da escola e os cancelamentos de matrículas. 0 material foi entregue, em fevereiro de 1994, ao Ministério Público.

No ano seguinte, no início de 1995, cinco anos depois de iniciada a pressão pela mudança, foi anulada a Resolução n. 9 e anunciada a n. 10 , reforçando justamente o direito ao ensino para as crianças e adolescentes estrangeiros, independentemente do status legal que se encontravam no país. Rege o documento que "a Direção da Escola deverá proceder à matrícula dos alunos estrangeiros sem qualquer discriminação, observando, no que couber, as mesmas normas regimentais que disciplinam a matrícula de alunos brasileiros nas escolas da rede estadual de ensino" (SECRETARIA DA EDUCAÇÃO, 1995, art. 2). Daí em diante, houve um árduo e longo processo até que cada unidade escolar não mais exigisse a documentação e não thes negasse direito ao 
boletim escolar ou ao certificado de conclusão de curso. Ainda hoje, são registrados entraves nesse sentido, ainda que a questão maior referente ao acesso à escola seja dada como resolvida.

Em 1997, um novo parecer do órgão reforçava a validade da resolução SE n. $10 / 95$, reafirmando não restar dúvidas de que os impedimentos do Estatuto do Estrangeiro estariam "tacitamente revogados por incompatibilidade, ficando inconsistente com os dispositivos constitucionais e legais hoje vigentes" (CONSELHO ESTADUAL DE EDUCAÇÃO, 1997). O documento explicita, ainda, não haver a necessidade de informar ao Ministério da Justiça sobre a presença de estudantes estrangeiros na escola, ação discriminatória e incoerente com os princípios da Constituição ou do Estatuto da Criança e do Adolescente.

Em 2008, o Conselho Estadual de Educação emitiu um terceiro parecer sobre o tema, reafirmando os dois anteriorese acrescentando ainda que "ao aluno estrangeiro deverá ser oferecido todo apoio pedagógico necessário para sua adaptação na série ou etapa em que foi classificado para que possa acompanhar os conteúdos curriculares da base nacional comum, especialmente no que se refere à aprendizagem da Língua Portuguesa”. Para não dar margem a controvérsias, o parecer ressalta ainda que "não há mais que se exigir o encaminhamento ao Ministério da Justiça dos dados de identificação do aluno estrangeiro sem RNE”, além de que "cabe à escola contribuir para esclarecer e orientar, se solicitada pela família, quanto aos procedimentos para regularização e garantia de seus direitos no país" (CONSELHO ESTADUAL DE EDUCAÇÃO, 1998).

Em 2004, a população imigrante residente na cidade de São Paulo passou a contar com outro parecer, desta vez do Conselho Municipal de Educação, que tratou tanto do direito à matrícula como ao certificado de conclusão de curso, independentemente de estar em situação regular no país. Diz o texto que:

(...) no sistema municipal de ensino de São Paulo, todas as crianças têm direito à educação, independentemente de sua situação legal. É dever do Estado matriculá-las, garantir-lhes o convívio educacional regular e, em caso de transferência, fornecer-lhes a documentação necessária e adequada à continuidade de estudos e, ao final do curso, conceder-lhes o respectivo histórico escolar e certificado de conclusão (CONSELHO MUNICIPAL DE EDUCAÇÃO, 2004).

Migrantes bolivianos nas escolas públicas de São Paulo

A distância entre o que está garantido legalmente e como isso se manifesta no cotidiano é um desafio em todos os campos dos Direitos Humanos, e neste em particular não é diferente. Em pesquisa de campo exploratória sobre o 
tema específico dos migrantes bolivianos nas escolas públicas de São Paulo (MAGALHAES, 2010), encontramos barreiras com relação às mais variadas dimensões do direito humano à educação. 0 acesso a essa educação é um primeiro fator que põe em xeque seu princípio de universalidade, na medida em que obstáculos emergem em diversos momentos da trajetória dos imigrantes. Para aqueles em situação irregular no país, ainda que a lei garanta esse direito, a falta de documentos ainda configura como um entrave para entrar (quando solicitam que demonstrem situação regularizada no Brasil), para mudar de escola (quando não facilitam o histórico escolar), e mesmo para sair (com a não emissão do certificado de conclusão de curso). Especialmente no caso dos que estão sem documentos, a burocracia e a falta de informações sobre os direitos educativos são os muros que parecem mais evidentes.

Uma vez dentro da escola, o olhar sobre a aceitabilidade dessa educação trouxe elementos importantes que caracterizam um ambiente que pouco promove a aprendizagem e desafia a promoção dos direitos humanos; ao contrário, caracteriza um ambiente discriminatório e, não raro, hostil à presença dessa população imigrante (MAGALHAES e SCHILLING, 2012). Este fenômeno em geral reproduz dentro da escola uma relação conflituosa que estabeleceram no bairro - xingamentos, provocações, episódios de violência.

A discriminação encontrada na mencionada pesquisa evidencia uma relação tensa que se trava dentro da escola, com uma urgente necessidade de mediações. E tais mediações estão fragilizadas, pois os professores e funcionários, ainda que já tenham notado a existência desses tensionamentos, transitam sem saber como agir, com poucos elementos para intervir em qualquer conflito dessa natureza.

No que tange, finalmente, à adaptabilidade desse direito, os desafios parecem de magnitude particular e, nesse ponto, o idioma é uma questão de partida a ser pensada em uma futura agenda de pesquisas sobre o tema, que inclui muitas outras questões em aberto.

MuROS E JANELAS: QUESTÕES PARA UMA AGENDA DE PESQUISAS

Em se tratando de um tema novo para a agenda de pesquisas, várias perguntas merecem ser feitas no sentido de suscitar reflexões e produção de conhecimento sobre o tema. Um ponto a considerar é o desafio da questão curricular: como garantir que o conteúdo trabalhado seja pertinente e, nesse contexto migratório, que questões que façam sentido aos migrantes também 
estejam presentes na escola? Por outro lado, interessa a eles manter seus valores anteriores? Quais são esses valores? Equais desejammanter?

Um tema correlato, levantado por Martins (2001, p. 25) é a relação entre escola e memória: como a escola lida com a memória? As sociedades ocidentais incluem, em suas técnicas de socialização do estrangeiro e do forasteiro, meios para promover o esquecimento cultural e social. Como combater essa “clandestinidade da memória”?

É necessário olhar de maneira particular os e as jovens nesse cenário, bem como as pessoas adultas, e a relação e inserção desses e dessas no mercado de trabalho, sobretudo informal, e suas alternativas de formação. Por outro lado, destaca-se que, tal como as pessoas adultas, a procura pela educação de jovens e adultos (EJA) é pouco considerada (MAGALHAES, 2010).

Finalmente, como se travam as relações de gênero entre meninos e meninas imigrantes dentro das escolas? As relações de gênero neste cenário conformam uma questão a ser mais bem explorada e compreendida.

Em que pesem os desafios da universalização de direitos em sociedades desiguais e discriminatórias, a busca pela realização plena do direito humano à educação deve incluir, para além do acesso em si, duas outras preocupações: os direitos humanos na educação e os direitos humanos através da educação. Pela definição contemporânea da realização desse direito, ele se realiza se todas as suas dimensões - disponibilidade, acessibilidade, aceitabilidade e adaptabilidade - forem protegidas, realizadas e promovidas de maneira conjunta. Assim, essa realização se condiciona também à pertinência do que está sendo ensinado e à existência de um ambiente que respeite e promova os direitos humanos. 


\section{The human right to education and contemporary international migrations: issues for a research agenda}

ABSTRACT: This paper aims to explore how the human right to education debate addresses migrant populations. As our analysis framework, we will consider the new characteristics of current international migration flows, a reality that is particularly noticeable in big cities, including major Brazilian cities. We will develop consideration regarding the current concept of the human right to education and will particularly focus on the following question: what does it mean to guarantee the human right to education to migrant whether they are in the country illegally or legally? Then, we will highlight the particular case of Bolivian immigrants in the city of Sao Paulo and the struggle for their educational rights in order to finally come up with some questions for a research agenda.

Key words: Human Right to Education. Educational Laws. Migrants. International Migration. 


\section{REFERÊNCIAS}

ARENDT, $H$. Origens do Totalitarismo: anti-semitismo, imperialismo, totalitarismo. São Paulo: Companhia das Letras, 1989.

BOBBIO, N. A Era dos Direitos. Rio de Janeiro: Campus, 1992.

BONASSI, M. Canta, América sem Fronteiras! Imigrantes Latino-americanos no Brasil. São Paulo: Loyola, 2000.

BRASIL. Lei no 6.815, de 19 agosto de 1980.

. Constituição . Constituição da República Federativa do Brasil. Brasília, DF, Senado, 1998. . Lei no 8.069, de 13 julho de 1990.

COMITÊ DE DIREITOS ECONÔMICOS, SOCIAIS e CULTURAIS das Nações Unidas, Observação Geral N. 13, 1999.

. Observação Geral N. 11, 1999.

SECRETARIA DA EDUCAÇÃO. Resolução 10/1995. Dispõe sobre matrícula de aluno estrangeiro na rede estadual de ensino fundamental e médio. São Paulo, 2 fev. 1995. Disponível em: http://siau.edunet.sp.gov.br/ItemLise/ arquivos/10_1995.htm

CONSELHOESTADUALDEEDUCAÇÃO. Parecer16/1997. Dispõe sobre a matrícula de aluno estrangeiro no ensino fundamental e médio do sistema de ensino do estado de São Paulo. São Paulo, 10 ago. 1997. Disponível em: http://iage. fclar.unesp.br/ceesp/cons_simples_listar.php?id_atos=56335\&acao=entrar. Acesso em: 02 de maio de 2013.

. Parecer 633/2008. Registro e Publicação de Diplomas e Certificados de Estrangeiros. São Paulo, 26 nov.2008. Disponível em: http://iage.fclar. unesp.br/ceesp/cons_simples_listar.php?id_atos $=66870 \&$ acao $=$ entrar. Acesso em: 02 de maio de 2013.

- Parecer 17/2004. Alunos estrangeiros de ensino fundamental sem Registro Nacional de Estrangeiro (RNE). São Paulo, 19 fev. 2004. Disponível em: http://www.prefeitura.sp.gov.br/cidade/secretarias/educacao/cme/pareceres/ index.php?p=958. Acesso em: 02 de maio de 2013.

DEMARTINI, Z.de B.F.; TRUZZI, O. (Org.). Estudos migratórios. Perspectivas metodológicas. São Carlos: Edufscar, 2005. 
DIAS, A. A. Da educação como direito humano aos direitos humanos como princípio educativo. In: SILVEIRA et al. (Org.). Educação em Direitos Humanos: fundamentos teórico-metodológicos. João Pessoa: Universitária, 2007.

FILHOS DE IMIGRANTES levam desvantagem nas escolas alemãs. Dwelle. 22 de out.de 2008.

FILHOS DE IMIGRANTES têm desvantagem na escola fundamental, aponta estudo. Dwelle. 9 de dez. de 2008.

HADDAD, S. A ação de governos locais na Educação de jovens e Adultos. Revista Brasileira de Educação. Rio de Janeiro, v. 12, n. 35. maio/ago 2007.

GENTILE, T. Itália quer limitar número de alunos imigrantes por sala de aula. Reuters, Brasil, 24 mar. 2009. Disponível em: 〈http://br.reuters.com/article/ newsOne/idBRSPE52N02420090324>. Acesso em: 9 ago. 2013

LAFER, C. A reconstrução dos direitos humanos: um diálogo com o pensamento de Hannah Arendt. São Paulo: Companhia das Letras, 1988.

MAGALHAES, G. M. Fronteiras do Direito Humano à Educação: um estudo sobre os imigrantes bolivianos nasescolas públicas de São Paulo Dissertação (Mestrado em Educação) - Faculdade de Educação da Universidade de São Paulo, 2010.

, SCHILLING, F. Imigrantes da Bolívianaescolaem São Paulo: fronteiras do direito à educação. Pro-Posições. Campinas, v. 13, n. 1 (67), p. 43-64. jan /abr 2012.

MARTINS, J. de S. Por uma pedagogia dos inocentes. Tempo Social: Rev. Sociologia USP, São Paulo, 13 (2): 21-30, Novembro de 2001.

MUÑOZ, V. The right to education of migrants, refugees and asylum-seekers. Relatório apresentado ao Conselho de Direitos Humanos da ONU. Genebra, A/HRC/14/25, 2010.

OPERA MUNDI. Partido neonazista grego cria programa "Médicos com Fronteira”. Opera Mundi. Redação, São Paulo. Disponívelem :http:// operamundi.uol.com.br/conteudo/noticias/25884/partido+neonazista+gre go+cria+programa+medicos+com+fronteira.shtml

ORGANIZAÇÃO DAS NAÇÕES UNIDAS. Declaração Universal dos Direitos Humanos, 1948. Disponível em: http://portal.mj.gov.br/sedh/ct/legis_ intern/ddh_bib_inter_universal.htm. 
. Convenção Internacional sobre a Proteção dos Direitos de Todos os Trabalhadores Migrantes e seus Familiares, 1990.

Pacto Internacional de Direitos Econômicos, Sociais e Culturais, 1966.

PRINCETON UNIVERSITY WOODROW WILSON SCHOOL OF PUBLIC AND INTERNATIONAL AFFAIRS. Free to learn: a rights based approach to universal primary education in Kenya. Princeton, 2006. Disponivel em: http://wws.princeton.edu/research/final_reports/f05wws591i.pdf. Acesso em: 1 de junho de 2010.

REIS, R. R. Políticas de Imigração na França e nos Estados Unidos. São Paulo: EditoraHucitec, 2007.

REUTERS BRASIL. Italia quer limitar número de alunos imigrantes por sala de aula. Reuters. 24 de março de 2009. Disponível em : http://br.reuters.com/ article/topNews/idBRSPE52N02420090324

SAYAD, A. A Imigração. São Paulo: EDUSP, 1998.

TOMASEVSKI, K. Human Rights Obligations in Education: The 4-A Scheme. Wolf, Nijmegen, 2006.

El asalto a la educación. Barcelona: Intermon-Oxfam, 2004.

RECEBIDO: Novembro de 2012.

APROVADO: Março de 2013. 